\section{BRAZIULIAN JOURNAL \\ OF MEDICAL AND BIOLOGICAL RESHARCH}

www.bjournal.com.br
ISSN 0100-879X

Volume 43 (7) 600-697 July 2010

BIOMEDICAL SCIENCES

AND

CLINICAL INVESTIGATION

Braz J Med Biol Res, July 2010, Volume 43(7) 651-656

doi: 10.1590/S0100-879X2010007500042

Repeated exposure of adolescent rats to oral methylphenidate does not induce behavioral sensitization or cross-sensitization to nicotine

C.C. Justo, P.E. Carneiro-de-Oliveira, R. DeLucia, M.L. Aizenstein and C.S. Planeta

The Brazilian Journal of Medical and Biological Research is partially financed by

Q

Ministério Conselho Nacional de Des
Cientifico e Tecrológico

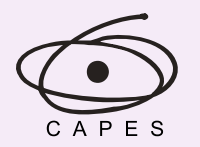

Ministério da Educação

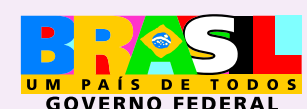

GOVERNO FEDERAL
DFAPESP

Institutional Sponsors
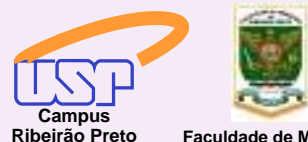

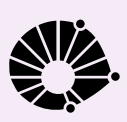

UNICAMP

UNICAMP
Ф SHIMADZU

GE Healthcare
Hotsite of proteomics metabolomics developped by:

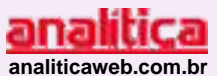

Thermo
SCIEN TIFIC 


\title{
Repeated exposure of adolescent rats to oral methylphenidate does not induce behavioral sensitization or cross-sensitization to nicotine
}

\author{
C.C. Justo ${ }^{1}$, P.E. Carneiro-de-Oliveira ${ }^{1,2}$, R. DeLucia $^{3}$, \\ M.L. Aizenstein ${ }^{3}$ and C.S. Planeta ${ }^{1,2}$ \\ ${ }^{1}$ Laboratório de Farmacologia, Faculdade de Ciências Farmacêuticas, \\ Universidade Estadual Paulista, Araraquara, SP, Brasil \\ ${ }^{2}$ Programa de Pós-Graduação em Ciências Fisiológicas, \\ Universidade Federal de São Carlos, São Carlos, SP, Brasil \\ ${ }^{3}$ Laboratório de Psicofarmacologia, Instituto de Ciências Biomédicas, \\ Universidade de São Paulo, São Paulo, SP, Brasil
}

\begin{abstract}
Several lines of evidence indicate that the use of stimulant drugs, including methylphenidate (MPD), increases tobacco smoking. This has raised concerns that MPD use during adolescence could facilitate nicotine abuse. Preclinical studies have shown that repeated treatment with an addictive drug produces sensitization to that drug and usually cross-sensitization to other drugs. Behavioral sensitization has been implicated in the development of drug addiction. We examined whether repeated oral MPD administration during adolescence could induce behavioral sensitization to MPD and long-lasting cross-sensitization to nicotine. Adolescent male Wistar rats were treated orally with $10 \mathrm{mg} / \mathrm{kg}$ MPD or saline (SAL) from postnatal day (PND) 27 to 33. To evaluate behavioral sensitization to MPD in adolescent rats (PND 39), the SAL pretreated group was subdivided into two groups that received intragastric SAL $(1.0 \mathrm{~mL} / \mathrm{kg})$ or MPD $(10 \mathrm{mg} / \mathrm{kg})$; MPD pretreated rats received MPD (10 mg/kg). Cross-sensitization was evaluated on PND 39 or PND 70 (adulthood). To this end, SAL- and MPD-pretreated groups received subcutaneous injections of SAL $(1.0 \mathrm{~mL} / \mathrm{kg})$ or nicotine $(0.4 \mathrm{mg} / \mathrm{kg})$. All groups had 8 animals. Immediately after injections, locomotor activity was determined. The locomotor response to MPD challenge of MPD-pretreated rats was not significantly different from that of the SAL-pretreated group. Moreover, the locomotor response of MPD-pretreated rats to nicotine challenge was not significantly different from that of the SAL-pretreated group. This lack of sensitization and cross-sensitization suggests that MPD treatment during adolescence does not induce short- or long-term neuroadaptation in rats that could increase sensitivity to MPD or nicotine.
\end{abstract}

Key words: Methylphenidate; Nicotine; Behavioral sensitization; Adolescent rats

\section{Introduction}

Attention deficit hyperactivity disorder (ADHD) is the most commonly diagnosed and treated psychiatric disorder of childhood. The psychostimulant methylphenidate (MPD), commonly known as Ritalin ${ }^{\circledR}$, is one of the most prescribed drugs for the treatment of ADHD. Children with ADHD are treated for several years, with drug administration often extending to adolescence and adulthood (1). MPD promotes many of the neurochemical effects typically associated with other psychomotor stimulants, including increases in extra- cellular dopamine and norepinephrine (2). These effects are mediated by MPD binding to the dopamine transporter and to the norepinephrine transporter, respectively, which blocks the neurotransmitters' transport through the nerve terminals (2). MPD may also act on serotonin transporters (3).

Adolescence is characterized by increases in novelty seeking and risk taking behaviors, which could predispose to drug abuse initiation (4). Exposure to psychostimulants during adolescence can have long-term consequences

Correspondence: C.S. Planeta, Laboratório de Farmacologia, Faculdade de Ciências Farmacêuticas, UNESP, Rod. Araraquara-Jaú, km 1, 14801-902 Araraquara, SP, Brasil. Fax: +55-16-3301-6980. E-mail: cplaneta@fcfar.unesp.br

Received December 7, 2009. Accepted April 7, 2010. Available online May 14, 2010. Published July 9, 2010. 
because early drug exposure may cause enduring adaptations, which render the organism more susceptible to drug abuse and relapse later in life $(5,6)$.

Converging lines of evidence indicate that the use of stimulant drugs, including MPD, increases tobacco smoking in the natural environment and under controlled laboratory conditions $(7,8)$. This has raised concerns that MPD use during adolescence could induce long-term changes that facilitate nicotine abuse. Indeed, preclinical studies also suggest that MPD may enhance the abuse-related effects of nicotine, which could be linked to increased vulnerability to tobacco smoking. This suggestion emerges from results showing that acute MPD increased the rate of nicotine self-administration and dose dependently enhanced the discriminative stimulus effect of a low nicotine dose in rats (9).

The mechanism underlying stimulant-induced increases in cigarette smoking is not clear; evidence from pre-clinical research suggests that the mesolimbic dopamine system may be the common pathway for this interaction. In fact, both psychostimulants and nicotine increase dopamine concentration in the nucleus accumbens $(10,11)$. Moreover, repeated exposure to nicotine has been shown to induce changes in the dopamine mesolimbic system that might be similar to those produced by psychostimulant drugs. For example, enhanced accumbal dopamine output (12) and increased locomotor response to the dopamine D1/D2 receptor agonist apomorphine have been reported following repeated exposure to nicotine (13). Repeated treatment with psychostimulants can induce behavioral sensitization as evidenced by an enhanced locomotor response to a subsequent injection of the drug $(14,15)$. Behavioral sensitization has been suggested as an animal model of neuroplasticity mainly associated with repeated administration of psychostimulant drugs and has been implicated in the development of drug addiction (14) and drug-induced psychosis (15). Repeated exposure to amphetamine, cocaine, fencamfamine, and methamphetamine has been shown to elicit behavioral sensitization (15-17). However, data of behavioral sensitization following repeated exposure to MPD have been contradictory, with reports of sensitization (18-21) and no sensitization (22).

It has been known that repeated treatment with an addictive drug produces sensitization to that drug and cross-sensitization to other drugs of abuse $(6,23)$. For example, it has been demonstrated that repeated exposure to nicotine sensitizes the locomotor response to cocaine and amphetamine in periadolescent rats $(24,25)$. It has also been demonstrated that long-term amphetamine $(6,26)$ or caffeine (26) induces behavioral sensitization to nicotine. However, at present the degree to which repeated MPD treatment during adolescence subsequently augments the locomotor response to nicotine is still unclear.

Although patients are treated with MPD orally, in most animal studies on MPD-induced behavioral effects, this drug was administered iv, ip, or sc. Evidence indicates that the behavioral effects of MPD significantly depend on the route of administration (22).

The aim of the present study was to examine whether repeated oral administration of MPD during adolescence could induce long-lasting behavioral sensitization to MPD and cross-sensitization to nicotine. For this purpose, rats were treated orally with $10 \mathrm{mg} / \mathrm{kg}$ of MPD from postnatal day (PND) 27 to 33 and locomotor activity was measured following a challenge injection of nicotine $(0.4 \mathrm{mg} / \mathrm{kg}, \mathrm{sc})$ on PND 39 and PND 70.

\section{Material and Methods}

\section{Animals}

Male periadolescent Wistar rats (PND 27) as defined by Spear (4) from the animal breeding facility of the São Paulo State University were used. Groups of 4 animals were housed in plastic cages measuring 32 (width) $\times 40$ (length) $x 16$ (height) $\mathrm{cm}$ in a room maintained at $21-23^{\circ} \mathrm{C}$. Rats were kept on a 12/12-h light/dark cycle (lights on at 7:00 am) and were allowed free access to food and water. All experiments were performed during the light phase. Control and experimental animals were randomly tested between 8:00 am and 5:00 pm. Periadolescent male rats were at PND 27 and weighed an average of $130 \mathrm{~g}$ at the beginning of the experiment. Testing of different experimental groups was counterbalanced across time, i.e., animals from different groups were evaluated on each test day.

The experimental protocol was approved by the Ethics Committee for use of Human or Animal Subjects of the School of Pharmaceutical Science - UNESP (CEP-34/2005) and was conducted according to the principles of the Brazilian College of Animals Experimentation (COBEA).

\section{Behavioral testing}

Behavioral testing was conducted in commercially available Plexiglas activity monitoring chambers (Columbus Instruments, USA). The chambers, measuring $42 \times 42$ $\mathrm{cm}$, included 10 pairs of photocells, which were used to measure the horizontal locomotor activity. The consecutive interruption of two beams was registered as one locomotion unit. The animals were allowed a 20-min adaptation period in the photocell apparatus before the injections and their locomotor activity was recorded immediately after the injections. Locomotion counts accumulated within 5-min intervals were recorded during a 15 -min or 45-min testing session following nicotine or methylphenidate injections, respectively. The test session duration was based on the fact that previous experiments from our laboratory showed that the locomotor effects of $0.4 \mathrm{mg} / \mathrm{kg}(\mathrm{sc})$ nicotine and 10 $\mathrm{mg} / \mathrm{kg}(\mathrm{po})$ methylphenidate were more prominent at these times (data not shown).

\section{Pretreatment}

Periadolescent rats were randomly divided into two 
groups that received $10 \mathrm{mg} / \mathrm{kg}$ methylphenidate hydrochloride (MPD; Ritalin ${ }^{\circledR}$, Novartis, Brazil) or saline (SAL) by gavage. Both groups were treated once daily for 7 days (PND 27-33). Ritalin ${ }^{\circledR}$ was dissolved in saline and the dose was calculated based on the molecular weight of the MPD salt.

\section{Behavioral sensitization to methylphenidate in adolescent rats}

From day 8 to day 12 the animals did not receive any treatment. On day 13 (PND 39; 6 days after the last injection in the pretreatment phase) the group pretreated with saline was subdivided into two groups that received SAL $(1.0 \mathrm{~mL} /$ $\mathrm{kg}, p o$ ) or MPD (10 mg/kg, po). The group pretreated with MPD received a challenge dose of MPD (10 mg/kg, po). Thus, the following groups were studied: $S A L+S A L(N=8)$, $\mathrm{SAL}+\mathrm{MPD}(\mathrm{N}=8)$, and MPD + MPD $(\mathrm{N}=8)$. Immediately after the oral administrations their locomotor activity was recorded as described above.

\section{Cross-sensitization}

Adolescent rats were pretreated with MPD or SAL as described above. After the last injection (on PND 33) the animals did not receive any treatment for 6 days. On PND 39, both SAL- and MPD-pretreated groups received a challenge dose of nicotine (NIC) $(0.4 \mathrm{mg} / \mathrm{kg}, s c)$ or SAL $(1.0 \mathrm{~mL} / \mathrm{kg}, \mathrm{sc})$.

A subset of adolescent rats received the same pretreatment as described above and remained in the plastic cages without any treatment for 35 days. On PND 70 (adulthood), both SAL- and MPD-pretreated groups received a challenge dose of NIC $(0.4 \mathrm{mg} / \mathrm{kg}, s c)$ or SAL $(1.0 \mathrm{~mL} / \mathrm{kg}, s c)$.

The groups of adolescent and adult rats studied on the test day were: SAL + SAL $(N=8), S A L+N I C(N=8)$ and MPD + NIC (N = 8). Immediately after the nicotine injections locomotor activity was determined as described above.

\section{Statistical analysis}

Data are reported as means \pm SEM. Locomotor activity for each age was analyzed by one-way ANOVA. When ANOVA showed statistical significance, further analyses were performed by the Newman-Keuls test.

\section{Results}

\section{Behavioral sensitization of adolescent rats to methylphenidate}

ANOVA showed significant differences in locomotor activity across groups $[F(2,21)=4.3 ; P<0.05]$ of adolescent rats (Figure 1). Pairwise comparisons indicated that the behavioral response to MPD was higher in saline- (SAL + MPD) and MPD- (MPD + MPD) pretreated groups compared to the SAL + SAL group. The behavioral response to MPD challenge of MPD-pretreated rats was not significantly different from that of the SAL-pretreated group, indicating the lack of behavioral sensitization.

\section{Cross-sensitization}

ANOVA showed significant differences in locomotor

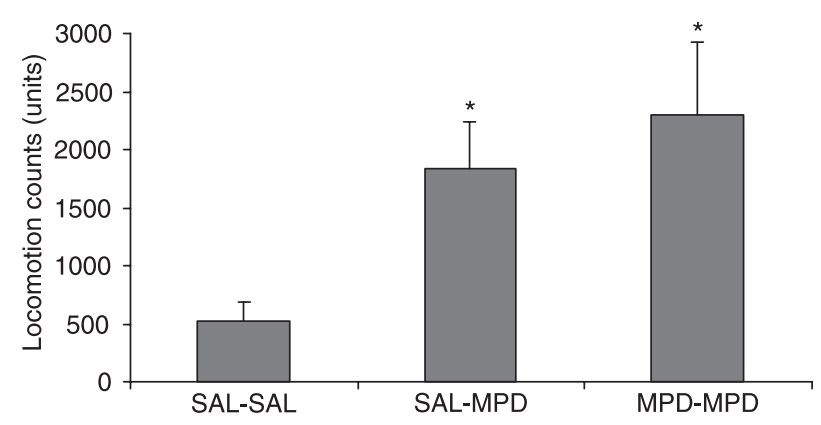

Figure 1. Methylphenidate (MPD)-induced locomotor activity in adolescent rats. Animals were pretreated with saline (SAL) or MPD (10 mg/kg, po) for 7 days from postnatal day (PND) 27 to 33. Six days after the last oral administration (PND 39), the animals received saline or MPD (10 mg/kg, po). The data are cumulative locomotion counts during 45-min periods after oral administration. Bars indicate the mean \pm SEM for 8 animals per group. ${ }^{*} P$ $<0.05$ compared to the SAL-SAL group (Newman-Keul test).
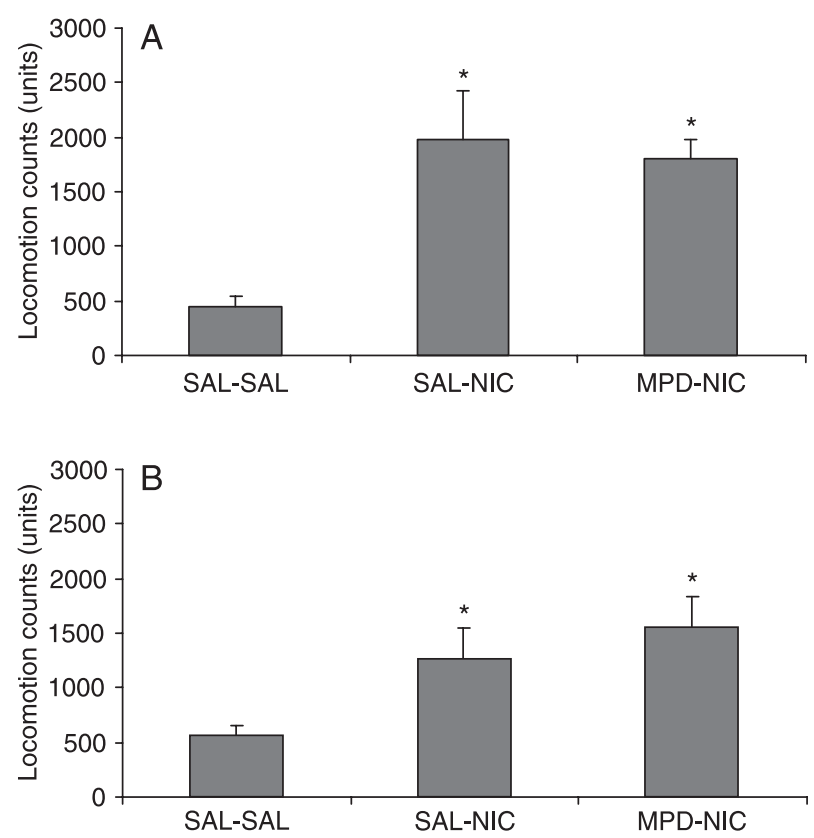

Figure 2. Nicotine-induced locomotor activity in adolescent $(A)$ or adult $(B)$ rats. Animals were pretreated with saline (SAL) or methylphenidate (MPD) (10 mg/kg, po) for 7 days from postnatal day (PND) 27 to 33. Six (PND 39) or 36 (PND 70) days after the last MPD administration, animals received SAL or nicotine (NIC, $0.4 \mathrm{mg} / \mathrm{kg}, \mathrm{sc}$ ). The data are cumulative locomotion counts during 15 -min periods after injection. Bars indicate the mean \pm SEM for 8 animals per group. ${ }^{*} \mathrm{P}<0.01$ compared to the SAL-SAL group (Newman-Keuls test). 
activity across groups of adolescent $[F(2,21)=8.67 ; \mathrm{P}<$ $0.01]$ and adult rats $[F(2,19)=4.52 ; P<0.05$; Figure $2 A$ and $\mathrm{B}$, respectively].

Comparisons across groups indicated for both adolescent and adult rats that nicotine significantly increased locomotor activity in both saline- (SAL + NIC) and MPD- (MPD + NIC) pretreated groups compared to the control (SAL + $\mathrm{SAL}$ ) group. The behavioral response of MPD-pretreated rats to NIC challenge was not significantly different from that of the SAL-pretreated group (MPD + NIC vs SAL + $\mathrm{NIC}$ ), indicating the lack of cross-sensitization.

\section{Discussion}

Our data demonstrated that repeated treatment with intragastric MPD did not induce behavioral sensitization in adolescent rats. Moreover, we did not observe crosssensitization between MPD and nicotine when the animals were challenged during adolescence or adulthood.

Several reports have demonstrated that repeated administration of MPD induces locomotor sensitization in adult animals $(18,21,27)$. In addition, Torres-Reveron and Dow-Edwards (19) reported that repeated ip administration of MPD produced behavioral sensitization in adult and adolescent rats.

In the present study, we found that repeated oral MPD administration during adolescence did not produce behavioral sensitization when the challenge injection of MPD was administered during the same age period (PND 39). This finding agrees with previous results showing that recurrent administration of MPD did not elicit behavioral sensitization in adolescent animals $(22,28)$.

A possible explanation for these inconsistent findings concerns methodological variations. Specifically, factors such as dose, time and route of administration, as well as the motor indices recorded, can critically affect the observation of behavioral sensitization. For example, studies on cocaine sensitization in developing animals have also yielded conflicting results depending upon the age tested, the drug dosage, the intervals between the repetitive drug treatment, and the challenge dose $(29,30)$. It has been shown that young animals chronically treated with stimulants rarely exhibit sensitization and, when sensitization occurs, it persists for a short period of time (31). The differences in circadian time of administration could also be one of the reasons for the inconsistent findings among several published reports. In a study in which MPD was injected at different times, only rats that were injected during the daytime between 8:00 am and 14:00 pm exhibited behavioral sensitization (27). In the present study, we cannot rule out the possibility that repeated intragastric administration was a stressful condition that could sensitize the animals to MPD, as previously shown for other drugs and stress conditions $(32,33)$. This could mask the observation of behavioral sensitization induced by repeated treatment with MPD.
Cross-sensitization between drugs of abuse is suggested to be one of the most reproducible paradigms to study whether exposure to the drug could increase vulnerability to the abuse of other substances. We investigated whether repeated treatment with oral MPD during adolescence could sensitize the animals to the locomotor effects of nicotine when the latter was administered during adolescence or adulthood. Our results showed a lack of cross-sensitization between MPD and nicotine at both ages tested.

Several studies have reported that repeated treatment with MPD during adolescence caused cross-sensitization to cocaine and amphetamine $(19,20,34)$. However, recently Guerriero et al. (28) showed that repeated MPD treatment of adolescent mice had no effect on locomotor sensitization to cocaine during adolescence or adulthood, suggesting that MPD treatment during adolescence does not induce long-term adaptations.

It has been shown that pre-exposure to nicotine enhances the subsequent locomotor stimulant effect of acute psychostimulants such as cocaine and amphetamine $(24,25)$. Nicotine-induced cocaine sensitization was observed in male and female periadolescent rats (24) while cross-sensitization between nicotine and amphetamine was observed only in male periadolescent rats (25). Pretreatment with nicotine did not sensitize male or female adult rats to a subsequent psychostimulant injection in either study.

Recently, Wooters et al. (9) examined in adult rats the effect of repeated nicotine exposure on subsequent MPD-induced hyperactivity. They showed that nicotine pretreatment $(0.2,0.4,0.6$, or $0.8 \mathrm{mg} / \mathrm{kg}$ for 10 days $)$ did not modify MPD-induced locomotor activity in response to the first injection administered 15 days after the last nicotine injection. This result suggests the lack of cross-sensitization between nicotine and MPD. However, Wooters et al. (9) observed that MPD sensitization emerged following the third injection of this drug in rats pretreated with the highest dose of nicotine.

To our knowledge, the present study is the first to examine the effects of MPD pretreatment on nicotineinduced locomotor activity. The result obtained is similar to that reported by Wooters et al. (9), showing the lack of cross-sensitization between nicotine and the first injection of MPD. In addition, based on Wooter's (9) results showing cross-sensitization between nicotine and MPD following repeated administration, we cannot exclude the possibility that pretreatment with MPD could alter nicotine-induced locomotor activity if nicotine was repeatedly injected.

The lack of cross-sensitization suggests that MPD treatment during adolescence does not induce short- or longterm neuroadaptations. Although the present study did not address the neuropharmacological mechanisms underlying the interactive effects of MPD and nicotine, this is an important subject for further research, particularly regarding the differences between the short- and long-term neuroadaptations induced by MPD and other psychostimulants in ado- 
lescent and adult animals. Although MPD promotes many of the neurochemical effects typically associated with other psychomotor stimulants, including increases in extracellular dopamine and norepinephrine $(2,3)$, there is evidence that the neuroadaptations induced by repeated MPD are different from those observed with other psychostimulants. In this regard, it has been found that the transcription factor "cAMP response element binding" (CREB) was persistently up-regulated in the nucleus accumbens following recurrent MPD treatment of periadolescent (PND 20-35) rats (35). Of note, total CREB protein was unchanged following recurrent cocaine administration in adult rats (36).

The present results also indicate the relevance of comparing adaptations following MPD administration by different routes. For instance, it has been shown that oral application of MPD to rodents increased extracellular norepinephrine in the hippocampus without significantly changing dopamine in the nucleus accumbens, which is essential for psychostimulants to induce behavioral sensitization (22). Gerasimov et al. (37) compared the effects of intraperitoneal and oral MPD administration on dopamine levels and locomotor activity and showed that ip MPD was approximately twice as potent as oral MPD both in increasing extracellular dopamine levels and in stimulating locomotor

\section{References}

1. Garland EJ. Pharmacotherapy of adolescent attention deficit hyperactivity disorder: challenges, choices and caveats. $J$ Psychopharmacol 1998; 12: 385-395.

2. Kuczenski R, Segal DS. Effects of methylphenidate on extracellular dopamine, serotonin, and norepinephrine: comparison with amphetamine. J Neurochem 1997; 68: 2032-2037.

3. Gainetdinov RR, Wetsel WC, Jones SR, Levin ED, Jaber $M$, Caron MG. Role of serotonin in the paradoxical calming effect of psychostimulants on hyperactivity. Science 1999; 283: 397-401.

4. Spear LP. The adolescent brain and age-related behavioral manifestations. Neurosci Biobehav Rev 2000; 24: 417463.

5. Cruz FC, Marin MT, Planeta CS. The reinstatement of amphetamine-induced place preference is long-lasting and related to decreased expression of AMPA receptors in the nucleus accumbens. Neuroscience 2008; 151: 313-319.

6. Santos GC, Marin MT, Cruz FC, Delucia R, Planeta CS. Amphetamine- and nicotine-induced cross-sensitization in adolescent rats persists until adulthood. Addict Biol 2009; 14: $270-275$.

7. Vansickel AR, Stoops WW, Glaser PE, Rush CR. A pharmacological analysis of stimulant-induced increases in smoking. Psychopharmacology 2007; 193: 305-313.

8. Cousins MS, Stamat HM, de Wit H. Acute doses of damphetamine and bupropion increase cigarette smoking. Psychopharmacology 2001; 157: 243-253.

9. Wooters TE, Neugebauer NM, Rush CR, Bardo MT. Methylphenidate enhances the abuse-related behavioral effects activity at doses of 5 and $10 \mathrm{mg} / \mathrm{kg}$. This was consistent with significantly higher plasma levels and brain uptake of $3 \mathrm{H}-\mathrm{MPD}$ observed after ip versus intragastric administration. The ability to reach peak levels within a short time is one of the main factors associated with the reinforcing properties and behavioral sensitization of MPD $(38,39)$. Therefore, oral MPD is infrequently reported as being abused (40). Drug abusers, in order to obtain its reward effects, habitually use systemic routes of MPD administration $(38,40)$.

Our findings showed that oral MPD exposure during adolescence does not result in behavioral sensitization to the locomotor effect of nicotine either in adolescent or adult rats. Further investigations on the interaction between MPD and nicotine may provide relevant information to understand the interplay between MPD use and tobacco smoking.

\section{Acknowledgments}

The authors appreciate the excellent technical assistance of Elisabete Zocal Paro Lepera and Rosana Finoti Pupim Silva. Research supported by FAPESP, grant \#05/02356-0 to C.C. Justo and \#04/01606-0 to C.S. Planeta. C.S. Planeta is the recipient of a CNPq research fellowship. of nicotine in rats: intravenous self-administration, drug discrimination, and locomotor cross-sensitization. Neuropsychopharmacology 2008; 33: 1137-1148.

10. Pontieri FE, Tanda G, Orzi F, Di Chiara G. Effects of nicotine on the nucleus accumbens and similarity to those of addictive drugs. Nature 1996; 382: 255-257.

11. Pontieri FE, Tanda G, Di Chiara G. Intravenous cocaine, morphine, and amphetamine preferentially increase extracellular dopamine in the "shell" as compared with the "core" of the rat nucleus accumbens. Proc Natl Acad Sci U S A 1995; 92: 12304-12308.

12. Shim I, Javaid JI, Wirtshafter D, Jang SY, Shin KH, Lee HJ, et al. Nicotine-induced behavioral sensitization is associated with extracellular dopamine release and expression of c-Fos in the striatum and nucleus accumbens of the rat. Behav Brain Res 2001; 121: 137-147.

13. Suemaru K, Gomita Y, Furuno K, Araki Y. Chronic nicotine treatment potentiates behavioral responses to dopaminergic drugs in rats. Pharmacol Biochem Behav 1993; 46: 135139.

14. Robinson TE, Berridge KC. The neural basis of drug craving: an incentive-sensitization theory of addiction. Brain Res Brain Res Rev 1993; 18: 247-291.

15. Robinson TE, Becker JB. Enduring changes in brain and behavior produced by chronic amphetamine administration: a review and evaluation of animal models of amphetamine psychosis. Brain Res 1986; 396: 157-198.

16. Aizenstein ML, Segal DS, Kuczenski R. Repeated amphetamine and fencamfamine: sensitization and reciprocal cross-sensitization. Neuropsychopharmacology 1990; 3: 
283-290.

17. Segal DS, Kuczenski R. Behavioral and neurochemical characteristics of stimulant-induced augmentation. Psychopharmacol Bull 1987; 23: 417-424.

18. Crawford CA, McDougall SA, Meier TL, Collins RL, Watson $\mathrm{JB}$. Repeated methylphenidate treatment induces behavioral sensitization and decreases protein kinase $A$ and dopamine-stimulated adenylyl cyclase activity in the dorsal striatum. Psychopharmacology 1998; 136: 34-43.

19. Torres-Reveron A, Dow-Edwards DL. Repeated administration of methylphenidate in young, adolescent, and mature rats affects the response to cocaine later in adulthood. Psychopharmacology 2005; 181: 38-47.

20. Valvassori SS, Frey BN, Martins MR, Reus GZ, Schimidtz F, Inacio CG, et al. Sensitization and cross-sensitization after chronic treatment with methylphenidate in adolescent Wistar rats. Behav Pharmacol 2007; 18: 205-212.

21. Yang PB, Swann AC, Dafny N. Chronic administration of methylphenidate produces neurophysiological and behavioral sensitization. Brain Res 2007; 1145: 66-80.

22. Kuczenski R, Segal DS. Exposure of adolescent rats to oral methylphenidate: preferential effects on extracellular norepinephrine and absence of sensitization and crosssensitization to methamphetamine. J Neurosci 2002; 22: 7264-7271.

23. Paro AH, Aizenstein ML, DeLucia R, Planeta CS. Repeated administration of caffeine increases femproporex-induced locomotor activity in adolescent and adult rats. Rev Bras Cienc Farm 2008; 44: 417-424.

24. Collins SL, Montano R, Izenwasser S. Nicotine treatment produces persistent increases in amphetamine-stimulated locomotor activity in periadolescent male but not female or adult male rats. Brain Res Dev Brain Res 2004; 153: 175187.

25. Collins SL, Izenwasser S. Chronic nicotine differentially alters cocaine-induced locomotor activity in adolescent vs adult male and female rats. Neuropharmacology 2004; 46: 349-362.

26. Celik E, Uzbay IT, Karakas S. Caffeine and amphetamine produce cross-sensitization to nicotine-induced locomotor activity in mice. Prog Neuropsychopharmacol Biol Psychiatry 2006; 30: 50-55

27. Gaytan O, Yang P, Swann A, Dafny N. Diurnal differences in sensitization to methylphenidate. Brain Res 2000; 864: 24-39.

28. Guerriero RM, Hayes MM, Dhaliwal SK, Ren JQ, Kosofsky $\mathrm{BE}$. Preadolescent methylphenidate versus cocaine treat- ment differ in the expression of cocaine-induced locomotor sensitization during adolescence and adulthood. Biol Psychiatry 2006; 60: 1171-1180.

29. Bowman BP, Kuhn CM. Age-related differences in the chronic and acute response to cocaine in the rat. Dev Psychobiol 1996; 29: 597-611.

30. Laviola G, Wood RD, Kuhn C, Francis R, Spear LP. Cocaine sensitization in periadolescent and adult rats. J Pharmacol Exp Ther 1995; 275: 345-357.

31. Barr GA, Wang S. Behavioral effects of chronic cocaine treatment in the week-old rat pup. Eur J Pharmacol 1993; 233: 143-149.

32. Araujo AP, Delucia R, Scavone C, Planeta CS. Repeated predictable or unpredictable stress: effects on cocaineinduced locomotion and cyclic AMP-dependent protein kinase activity. Behav Brain Res 2003; 139: 75-81.

33. Araujo NP, Camarini R, Souza-Formigoni ML, Carvalho RC, Abilio VC, Silva RH, et al. The importance of housing conditions on behavioral sensitization and tolerance to ethanol. Pharmacol Biochem Behav 2005; 82: 40-45.

34. Schenk S, Izenwasser S. Pretreatment with methylphenidate sensitizes rats to the reinforcing effects of cocaine. Pharmacol Biochem Behav 2002; 72: 651-657.

35. Andersen SL, Arvanitogiannis A, Pliakas AM, LeBlanc C, Carlezon WA Jr. Altered responsiveness to cocaine in rats exposed to methylphenidate during development. Nat Neurosci 2002; 5: 13-14.

36. Nestler EJ. Molecular neurobiology of addiction. Am J Addict 2001; 10: 201-217.

37. Gerasimov MR, Franceschi M, Volkow ND, Gifford A, Gatley SJ, Marsteller D, et al. Comparison between intraperitoneal and oral methylphenidate administration: A microdialysis and locomotor activity study. J Pharmacol Exp Ther 2000; 295: 51-57.

38. Kollins SH. Comparing the abuse potential of methylphenidate versus other stimulants: a review of available evidence and relevance to the ADHD patient. J Clin Psychiatry 2003; 64 (Suppl 11): 14-18.

39. Leonard BE, McCartan D, White J, King DJ. Methylphenidate: a review of its neuropharmacological, neuropsychological and adverse clinical effects. Hum Psychopharmacol 2004; 19: 151-180.

40. Kollins SH, MacDonald EK, Rush CR. Assessing the abuse potential of methylphenidate in nonhuman and human subjects: a review. Pharmacol Biochem Behav 2001; 68: 611-627. 